\title{
ADEQUAÇÃO DA PRODUÇÃO DE SERVIÇOS TERCEIRIZADOS DE UMA CONFECÇÃO:
}

\author{
UM Estudo de CASO
}

\author{
Alini Cavichioli ${ }^{1}$ \\ Antonio José dos Santos ${ }^{2}$ \\ Cristiane Luiza Bleich Vetore ${ }^{3}$ \\ Daniele Cristina Gelain Rezende ${ }^{4}$ \\ Giancarlo Steffani ${ }^{5}$ \\ Wallace Nóbrega Lopo ${ }^{6}$
}

\section{ResUmo}

O presente artigo é um estudo de caso que tem por objetivo analisar a adequação da produção de serviços terceirizados de uma pequena empresa do ramo de confecção de vestuário situada na cidade de Guabiruba - SC, que faz parte de um segmento intitulado de prestadora de serviços de costura de artigos de malha de linha básica. Os dados foram pesquisados de forma qualitativa com aplicação de um questionário previamente elaborado pelos autores e respondido pelo socioproprietário da fábrica que aqui denominamos de Confecções Cavichioli. O contato foi realizado de forma pessoal, obtendo-se informações a respeito do histórico de demanda dos últimos dois anos, capacidade produtiva, fluxo de produção, layout e uso de célula de confecção. A partir das propostas de Tubino (2009), Slack et al. (2002), Toledo (1992) entre outros citados neste artigo, foi possível confrontar a literatura com as práticas da cadeia produtiva investigada. Identificou-se que a previsão de demanda, baseada na capacidade produtiva da empresa, mostrou-se mais eficiente do que aquela relacionada ao histórico de produção e que a modificação do layout do maquinário, junto com a alteração para um sistema produtivo em célula e por batelada, apresentou o melhor resultado para o atendimento da demanda exigida pelo mercado.

Palavras-Chave: Confecção do vestuário. Célula de confecção. Previsão da demanda. Capacidade produtiva.

\section{$* * *$}

1. Especialista, e-mail: alinicavichioli@ hotmail.com

2. Mestre, e-mail: antoniodos.santos@ bol.com.br

3. Especialista, $e$-mail: cristiane.luiza@ yahoo.com.br

4. Especialista, e-mail: danielegelain@gmail. com

5. Especialista, $e$-mail: carlogian2@hotmail. com

6. Especialista, e-mail: w.lopo@uol.com.br

$* * *$ 


\section{INTRODUÇÃO}

Existe uma necessidade pela busca do "novo", a internet $\mathrm{e}$ as novelas nos instigam a querer o novo, criam o desejo de possuir aquele produto que está na mídia.

Araujo (1996) define confecção como sendo "a nossa segunda pele”, com funções pragmáticas, estéticas e representativas, e que vem evoluindo constantemente.

\section{PARA ATENDER A ESSA NECESSI- DADE CRESCENTE, AS EMPRESAS TERCEIRIZADAS VÊM OCUPANDO UM LUGAR DE DESTAQUE NO SETOR DE VESTUÁRIO.}

Giosa (1993) aponta que as atividades terceirizadas podem conduzir a um maior controle de qualidade, redução dos desperdícios, retrabalhos, o que vem tornando as empresas mais competitivas em meio à globalização econômica.

Já Brasil (1993) define terceirização como sendo um processo de transferência, dentro da empresa - "empresa-origem", de atividades que podem ser executadas por outras empresas - "empresa-destino". Tal processo vem sendo cada vez mais utilizado pela empresa na busca de aumentar a sua competitividade perante a um mercado tão exigente.

Num primeiro momento, o presente trabalho investiga, na literatura, sobre Célula de
Produção em Confecção, seus tipos e diferenças entre essas células. Num segundo momento, a partir da literatura pesquisada, sinaliza a previsão da demanda e quais as tecnologias existentes (instrumentos e ferramentas) que auxiliam no melhor gerenciamento da demanda. Na sequência, trata do conceito de planejamento e a estratégia utilizada no atendimento da demanda e sobre a capacidade produtiva. Por fim, descreve o diagrama espaguete e os tipos de processos produtivos.

Do ponto de vista dos seus objetivos, o presente artigo é um estudo de caso, um estudo empírico que analisa um fenômeno atual pertencente ao contexto de realidade.

O estudo foi realizado por meio de pesquisa descritiva. As pesquisas desse tipo têm como função a descrição das características de determinada população e situações ou ainda a relação entre elas (GIL, 1999). Optou-se por esse tipo de pesquisa por descrever as características do fenômeno da previsão de demanda na produção de serviços terceirizados de confecção, a partir de dados extraídos da empresa em estudo.

Sobre os procedimentos técnicos, ele também é bibliográfico, visto que se buscou investigar, na literatura e também na empresa estudada, a capacidade produtiva, o fluxo de produção, o layout e a célula de confecção.

A forma de coleta das informações junto ao socioproprietário foi por meio de contato pessoale de entrevista com perguntas estruturadas. 


\section{CÉLULA DE PRODUÇÃO EM CONFECÇÃO}

Antes da década de 50, a produção de confecções tinha a filosofia de confeccionar uma peça de vestuário, de maneira individualizada, ou seja, uma mesma costureira produzia uma única peça de cada vez e realizava todas as etapas dessa tarefa.Isso obrigava a utilização de uma grande quantidade de mão de obra para produção de grandes volumes.

A PARTIR DESSA DÉCADA, FA-

BRICANTES DE MÁQUINAS DE

COSTURA E PROfiSSIONAIS DA

PRODUÇÃO DE CONFECÇÕES

COMEÇARAM A ESTUDAR NO-

VAS TÉCNICAS QUE PUDESSEM,

ALÉM DE AUMENTAR A PRO-

DUTIVIDADE NA FABRICAÇÃO,

DIMINUIR A MÃO DE OBRA

ENVOLVIDA.

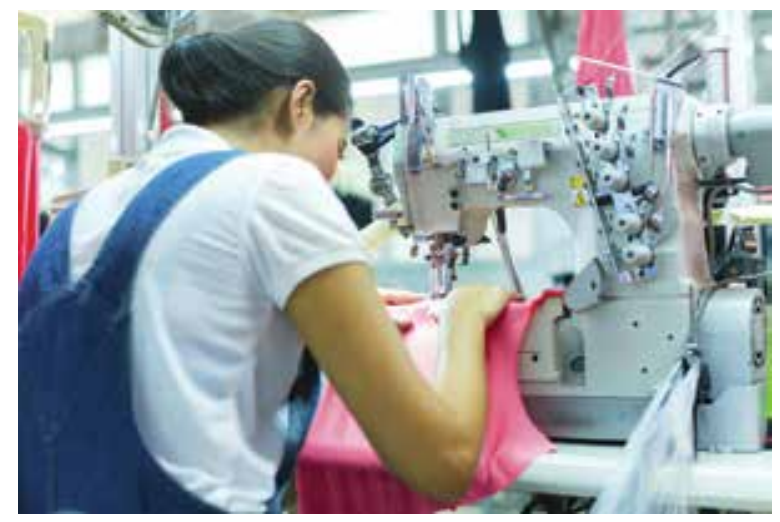

Surgiu, então, o conceito de célula de produção em confecção. O que a caracteriza é a fabricação de um único tipo de peça, produzida por várias máquinas e cada uma delas exercendo uma função diferente no produto. (TOLEDO, 1992).

As células de produção em confecção se diferenciam entre si, de acordo com o modelo do confeccionado que será produzido e a quantidade do mesmo. Essa diversificação do produto pode ser dividida em quatro séries. $\mathrm{O}$ quadro 1 mostra as diferenças entre essas séries, com suas descrições e exemplos.

Quadro 1: Grau de diversificação do produto

\begin{tabular}{|c|c|c|c|c|}
\hline Tipo de produção & Descrição & \multicolumn{3}{|c|}{ Exemplo de gama de modelos } \\
\hline Grande série & $\begin{array}{l}\text { Um tipo de vestuário em } \\
\text { produção do mesmo modelo } \\
\text { por muitas semanas; modelo } \\
\text { seguinte, apenas com algu- } \\
\text { mas alterações de constru- } \\
\text { ção, muitas semanas. }\end{array}$ & $\begin{array}{l}30.000 \text { calças } \\
\text { básicas na } \\
\text { mesma cor e } \\
\text { tecido. }\end{array}$ & $\begin{array}{l}40.000 \text { calças } \\
\text { no mesmo } \\
\text { tecido, em } \\
\text { duas cores, } \\
\text { com bainha. }\end{array}$ & $\begin{array}{l}35.000 \text { calças } \\
\text { do mesmo } \\
\text { tecido e cor, } \\
\text { com bolsos } \\
\text { inclinados. }\end{array}$ \\
\hline Série média & $\begin{array}{l}\text { Um tipo de vestuário e mui- } \\
\text { tos modelos que se repetem } \\
\text { com frequência, cada um } \\
\text { tendo pequenas variações; } \\
\text { existe, normalmente, uma } \\
\text { mistura de muitas partidas } \\
\text { pequenas de diferentes es- } \\
\text { tilos em produção. }\end{array}$ & $\begin{array}{l}400 \text { camisas } \\
\text { em oito teci- } \\
\text { dos e } 20 \text { cores, } \\
\text { com punho } \\
\text { simples e bai- } \\
\text { nha a direito. }\end{array}$ & $\begin{array}{l}500 \text { camisas } \\
\text { em dez teci- } \\
\text { dose } 16 \text { cores, } \\
\text { com punho } \\
\text { duplo, bai- } \\
\text { nha redonda } \\
\text { e bolso. }\end{array}$ & $\begin{array}{l}300 \text { camisas } \\
\text { em quatro } \\
\text { tecidos e } 20 \\
\text { cores, pu- } \\
\text { nho simples, } \\
\text { bainha a di- } \\
\text { reito, bolso e } \\
\text { cintadas. }\end{array}$ \\
\hline
\end{tabular}




\begin{tabular}{|c|c|c|c|c|}
\hline Tipo de produção & Descrição & \multicolumn{3}{|c|}{ Exemplo de gama de modelos } \\
\hline Moda & $\begin{array}{l}\text { Um tipo de vestuário, com } \\
\text { grande variedade de mode- } \\
\text { los, alimentado um de cada } \\
\text { vez em partidas de tamanho } \\
\text { médio. }\end{array}$ & $\begin{array}{l}5.000 \text { calças } \\
\text { do mesmo te- } \\
\text { cido em duas } \\
\text { cores, cinto } \\
\text { estreito e bol- } \\
\text { sos laterais. }\end{array}$ & $\begin{array}{l}4.000 \text { calças } \\
\text { do mesmo } \\
\text { material, só } \\
\text { numacor,sem } \\
\text { cinto, bolsos } \\
\text { de chapa e } \\
\text { cartela com } \\
\text { botões. }\end{array}$ & $\begin{array}{l}6.000 \text { calças } \\
\text { do mesmo } \\
\text { material em } \\
\text { três cores, } \\
\text { comcintoalto } \\
\text { e justo e sem } \\
\text { bolsos. }\end{array}$ \\
\hline Grande moda & $\begin{array}{l}\text { Produção de mais de um tipo } \\
\text { de vestuário, geralmente em } \\
\text { partidas relativamente pe- } \\
\text { quenas de tipos de vestuário } \\
\text { diferentes em sequência. }\end{array}$ & $\begin{array}{l}4.000 \text { vestidos } \\
\text { do mesmo } \\
\text { material em } \\
\text { seis cores com } \\
\text { gola e punhos } \\
\text { a constatar, } \\
\text { botões na } \\
\text { frente e cinto. }\end{array}$ & $\begin{array}{l}2.000 \text { saias do } \\
\text { mesmo ma- } \\
\text { terial, quatro } \\
\text { cores, cinto, } \\
\text { fecho e bolso } \\
\text { de chapa. }\end{array}$ & $\begin{array}{l}5.000 \text { vestidos } \\
\text { emcincocores } \\
\text { e num tecido, } \\
\text { xadreza casar, } \\
\text { sem mangas, } \\
\text { decote qua- } \\
\text { drado e fecho } \\
\text { lateral. }\end{array}$ \\
\hline
\end{tabular}

Fonte: Araujo (1996)

Como podem serobservados, esses quatro tipos de produção possuem características diferentes. Isso demandará na utilização de diferentes células de produção na confecção, que deverá ser a mais racional e eficiente para cada tipo de produção e produto.

TOdAS AS CÉLULAS DE PRODUÇÃO NA CONFECÇÃO DEVEM SER ANALISADAS, TENDO EM VISTA QUE ESSES SISTEMAS PODEM SER AMPLAMENTE MODIfiCADOS DE ACORDO COM A QUANTIDADE DE MODELOS E OUTRAS CONDIÇÕES ENCONTRADAS EM CADA EMPRESA. (ARAUJO, 1996).

Os tipos de células de produção convencionais podem ser divididos em quatro e são assim classificados: a) Sistema de célula com mesa ou tapete rolante:

Este sistema confecciona peças individuais, numa sequência de operações consecutivas, executadas ao lado de uma mesa de transporte ou um tapete rolante. As operações são divididas de forma que cada operador faça sua tarefa no mesmo tempo e a velocidade do transporte (mesa ou tapete) seja definida conforme esse tempo.

O sistema em si pode ser considerado muito inflexível, devido à necessidade de se dividir a montagem da peça em operações com o mesmo tempo.Esse tipo de célula poderá ter duas linhas de costuras, uma em cada lado da mesa, o que poderá aumentar e produção da linha, mas não a produtividade.

b) Sistema de célula com rampas (synchro flow):

O sistema com rampas é utilizado quando uma das etapas da costura possuium tempo maior para ser executado e, com isso, há a necessidade de se colocar duas máquinas para executar tal tarefa. 
As partes da peça são passadas para o operador seguinte, através de uma rampa, em que se acumula um pequeno estoque intermediário; se bem coordenado, não aumentará o tempo de produção da confecção.

Essa célula ocupa uma área maior que a anterior, porém, permite-nos trabalhar com modelos mais complexos.

c) Sistema de célula com lote progressivo:

Nesta célula as operações são implantadas em sequência com um chamado reservatório de trabalho em curso ou de produto em processo em espera para cada uma delas. Cada operador trabalha na sua própria velocidade retirando novos lotes de trabalho em andamento, que estão esperando nos reservatórios, ou seja, poderá haver várias peças juntas com o mesmo operador.

Nesta célula, ocasionalmente, transferem-se operadores de uma operação para outra, a fim de equilibrar o fluxo de produção.

Os reservatórios deverão ser dimensionados de acordo com o tipo de peça e volume de produção, e poderão ser substituídos por outras que melhor se adaptam ao próximo produto, por conta disso, deverão ser móveis, com a utilização de rodinhas ou pranchas móveis.

Visando equilibrar o fluxo de utilização de transportadores de lotes, para algumas operações, tais transportadores poderão ser cavaletes, caixas, araras de cabides etc.

d) Sistema de célula com interfluxo (interflow):

Este sistema de célula é utilizado quando uma variedade de produtos é canalizada através de uma complexa quantidade de operações especializadas. Com a implantação fixa da máquina para facilitar um fluxo progressivo de um operador para outro, esse sistema permite a mudança da sequência de operações, quanto ao modelo, em oposição ao sistema de lote progressivo, já visto anteriormente.

Com a possível e real mudança contínua de operações, em alguns casos, torna-se necessária a implantação de sistema de transporte de peças e acessórios, via tapete rolante e equipamentos convencionais de armazenamento intermediário de material a ser confeccionado, de forma a tornar o sistema de células interfluxo mais flexível e eficiente.

e) Sistemas decéluladeproduçãoavançados:

Hoje em dia, diante da necessidade de se aumentar a produtividade e diminuir os custos no setor de confecção, utilizam-se sistemas de células de confecção mais avançadas do que as quatro convencionais, já explicadas anteriormente.

Tais sistemas visam facilitar e agilizar a produtividade, quando das seguintes necessidades:

- mudança rápida das regulagens e acessórios das máquinas;

- versatilidade dos operadores para que possam executar qualquer tipo de operação;

- lote unitário;

- fazer bem a primeira vez (zero defeito);

- tempo das peças em produção muito curto (tempo EM produção = tempo DE produção);

- trabalho em grupo ou equipe;

- forte motivação do grupo;

- ideia de fluxo contínuo de produção;

- inexistência de produto em processo em espera. 
Desses sistemas de célula de produção em confecção, podemos considerar dois tipos:

a) Sistema de célula de produção unitário - UPS (Unit Production System):

Este sistema tem como principal característica a integração de estações de trabalho ergonômicas em uma contínua transmissão ou transferência das partes das peças do vestuário em transporte aéreo, utilizando, para isso, um sistema de cabides e trilhos.

Nesse Sistema, O ENDERE-

ÇAMENTO DOS CABIDES DE

UM OPERADOR PARA OUTRO É

REALIZADO POR UM COMANDO

VIA SOftWARE QUE DIRECIONA

A PEÇA CORRETA PARA O SEU

DESTINO CORRETO.

Isso torna o sistema mais flexível, podendo trabalhar com mais de um modelo diferente, ao mesmo tempo.

Esse sistema é conhecido como Eton ${ }^{\circledR}$, e controla os fluxos individuais de cada cabide em processo, por meio da monitoração das estações de trabalho (costureiras), definindo as operações necessárias, viabilizando o atendimento simultâneo da produção de grandes variações de modelo e dando prioridade às entregas mais urgentes, dentro do sistema.

b) Sistema de célula de produção de fabricação modular:

Os sistemas deste tipo de célula foram desenvolvidos para permitir a rápida resposta a mudanças nos mercados e, como consequência dos modelos a serem produzidos, permitindo um elevado grau de diversificação da produção.
Embora exista no mercado uma variedade de sistemas desse tipo, um dos aspectos mais importantesé o conceito de fluxo contínuo de peças individualizadas (lote unitário) envolvendo uma pequena equipe de operadores multifuncionais para trabalhar em equilíbrio.

Os fluxos são bem complexos, devido a isso, a utilização de um programa para definir e direcionar as peças para os locais de trabalho se torna indispensável.

\subsection{Previsão da demanda}

Diversas empresas têm buscado cada vez mais conhecer novas técnicas de previsão de demanda. Com o advento das tecnologias, essas técnicas vêm melhorando ano após ano.
A previsão da demanda precisa ser realiza- da com cautela, devido ao grande impacto que é gerado dentro da empresa no setor de produção. Tais impactos são sentidos não só na produção, mas nos outros setores da empresa.

Slack et al. (2002) relata sobre o uso do MRP (Material Requirement Planning) e os reais benefícios do uso desta ferramenta. Com ela é possível calcular as reais necessidades dos materiais no momento em que se necessita. Já o MRP II (Manufacturing Resources Planning) auxilia as empresas no planejamento das decisões com antecedência, na gestão de compras, estoques, financeira, produção e logística.

Tubino (2009) reforça a importância da coleta e análise dos dados históricos, pois eles são mais confiáveis à técnica de previsão. Promoções especiais ou greves precisam ser analisadas e substituídas por valores médios. Os dados devem buscar a demanda pelos produtos da empresa, pois geralmente não são iguais às 
vendas passadas. E, por último,é preciso definir o tamanho do período de consolidação dos dados (semanal, mensal, anual etc.)

\section{Após definida a técnica de previsão, aplicando dados passados para obter os parâmetros, pode-se então realizar as projeções futuras da demanda.}

Quanto mais longe pretendemos vislumbrar, menor será a confiabilidade da demanda prevista. (TUBINO, 2009).

Segundo Popadiuk e Santos (2010), o planejamento de demanda pode ser dividido em quatro grandes grupos: "conhecimento cultural", em que as empresas definem seus objetivos, metas e pretensões. O segundo é o "conhecimento explícito", que trata de informações e conhecimentos utilizados na elaboração da previsão. Já o terceiro grupo é o "conhecimento tácito", que se refere ao respeito pela bagagem de conhecimento dos profissionais da empresa e, por último, o "conhecimento tácito relacionado à interação e transferência”, que trata da interação entre os profissionais no ambiente de trabalho.

\subsection{Conceitos de planejamento}

Corrêa et al. (2012) define o planejamento como um conjunto de considerações do momento presente e da visão de futuro onde serão tomadas decisões no presente para que se atinjam determinados objetivos no futuro.

Planejar É Projetar um FuTURO, UM FUTURO DIFERENTE DE UM PASSADO VIVIDO.
A dinâmica do processo de planejamento, segundo Corrêa et al. (2012), é dividido em cinco passos:

1. verificar a situação presente;

2. desenvolver e reconhecer o que se deseja para o futuro;

3. analisar os dois passos anteriores juntos para a tomada de decisão;

4. tomar a decisão sobre o que, quanto, quando produzir e comprar com os recursos disponíveis;

5. executar o plano.

Esses passos auxiliam na tomada de decisões, visto que o ato de planejar nos fornece um horizonte de onde e como devemos chegar para atender aos objetivos da empresa.

\subsection{Estratégias para o atendimento da demanda}

A capacidade de atendimento da demanda é de responsabilidade da administração da produção, esta responsabilidade deveria envolver também outras áreas da empresa, como o departamento comercial por exemplo. Slacket al.(2002) dizem que embora planejar e controlar a capacidade seja uma das principais responsabilidades dos gerentes de produção, também deveria envolver outros gerentes funcionais, pois este processo tem impactos que podem envolver toda empresa.

Cada modelo de negócio emprega também mecanismos diferentes na tomada de decisão sobre as estratégias adotadas visando atender e satisfazer a demanda atual e futura, para que isso ocorra de forma adequada, a empresa deverá ter seu nicho competitivo muito bem definido, 
e compreender quem é seu cliente, o que ele procura: preço, qualidade, flexibilidade, dentre outros, assim poderá formular uma estratégia de acordo com a necessidade do mercado em que ela atua. Adequações ao longo do processo muitas vezes são necessárias para que sejam evitadas as indesejáveis vendas perdidas e também o acúmulo desnecessário de estoques. Dessa forma, um bom planejamento estratégico se faz necessário para maximizar os resultados das operações e minimizar os riscos nas tomadas de decisões das empresas. Segundo Tubino (2009), decisões no planejamento estratégico da produção afetam decisões de longo prazo e afetam a natureza e características das empresas no sentido de garantir o atendimento de sua missão.

\subsection{Capacidade produtiva}

Capacidade produtiva pode ser entendida como o grau de atividade definido pela capacidade dos recursos disponíveis (máquinas, mão de obra, espaço, tempo etc.) a fim de atender a uma determinada demanda, solicitação de um cliente. (MENEZES, 2010).

Para Johnston e Clark (2010), não existe uma forma perfeita de gerenciar a capacidade produtiva; estratégia de gestão de capacidade produtiva deve estar aliada ao modelo básico do negócio da empresa. Percebe-se que a tomada de decisão sobre a estratégica para o atendimento de demanda não é simples, visto que envolve estrutura da operação, metas estabelecidas, demanda atual e demanda futura. Há que se considerar ainda a disponibilidade de recursos da empresa, pois eles podem se tornar caros ou escassos.

Slack et al. (2002) observam a importância da gestão da administração da capacidade produtiva pelo departamento de gestão da produção, como sendo uma área de fundamental importância para o andamento de todo o processo produtivo e de atendimento dos pedidos solicitados, com perspectivas definidas a longo, médio e curto prazo.

Para atender às flutuações de demanda, Slack et al. (2002) propõem três opções para lidar com as variações:

a) Política de capacidade constante: o processamento é realizado em um nível contínuo em todo o período de planejamento, não considerando as flutuações de previsão de demanda.

b) Política de acompanhamento de demanda: consiste em uma política que busca ajustar a capacidade de produção o mais próximo possível dos níveis variáveis de demanda prevista.

VARIADAS ALTERNATIVAS PO-

DEM SER UTILIZADAS NO CASO

DA ADOÇÃO DESTA ESTRATÉGIA,

TAIS COMO: UTILIZAÇÃO DE

HORAS EXTRAS E TEMPO OCIO-

SO, VARIAÇÃO DO TAMANHO DA

FORÇA DE TRABALHO, USO DE

PESSOAL EM TEMPO PARCIAL, SUBCONTRATAÇÕES. 
c) Gerenciar a demanda: consiste em utilizar mecanismos para melhor distribuição da demanda. Este modelo de estratégia é comumente utilizado por empresas que possuem sazonalidades em suas produções, como é o caso da indústria do vestuário.

Existem variadas formas de efetuar o gerenciamento de demanda, as mais utilizadas são: alteração de preço, desenvolvimento de novos produtos, novos serviços, dentre outras políticas que podem ser criadas para preencher a capacidade em períodos considerados tranquilos.

d) Políticas mistas: quando uma das três políticas consideradas "puras" não atende aos objetivos competitivos e operacionais da empresa e suas vantagens não compensem as desvantagens, as empresas escolhem adotar uma combinação das três abordagens.

O cenário para definição da capacidade produtiva se torna mais complicado quando é verificada a complexidade de atendimento ao setor de serviços. Esse setor mostra-se com um elevado grau de dinamismo, o que faz com que o entendimento das necessidades dos clientes seja feito visando à adequação de todo processo produtivo às variações de demanda sem, no entanto, reduzir níveis de eficiência ou qualidade. (MENEZES,2010;LACERDA;TEIXEIRA, 2009).

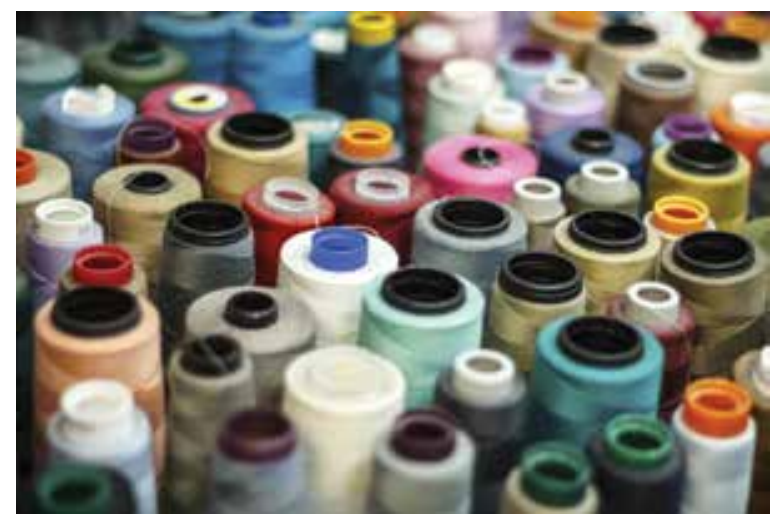

NO CASO DO SETOR DE VES-

TUÁRIO, EXISTE AINDA OUTRA

CARACTERÍSTICA QUE DEfINE

SEU MODELO DE NEGÓCIO E

INVIABILIZA MUITAS VEZES

A DECISÃO POR UMA OU OU-

TRA POLÍTICA DE ADEQUA-

ÇÃO DA PRODUÇÃO QUE É A

SAZONALIDADE.

Isso ocorre porque ela atua em um mercado considerado rápido. A confecção muda suas coleções normalmente conforme as estações do ano ou, no mínimo, duas vezes ao ano, inverno e verão, o que significa que a cada mudança de coleção são criados e produzidos novos produtos. Entre uma coleção e outra, ocorre o período da sazonalidade.Tubino (2009) afirma que, quando os valores de uma quantidade se desviam da média de série ou de uma tendência, significa que existe a sazonalidade, por esse motivo também há de se considerar este dado no momento da previsão de demanda.

Em quase todas as organizações, o planejamento precisa lidar com as flutuações de sazonalidade de demanda, o que implica um planejamento que se adeque a essas flutuações, logo o planejamento deve também considerar o tempo que os clientes estão dispostos a esperar. (SLACK et al, 2002).

A diferença entre demanda e capacidade, apresentada na figura 1 , pode restringir o potencial do prestador de serviços em atender às necessidades dos clientes, gerando atrasos quando do aumento de demanda; um nível de ociosidade quando da diminuição da demanda; ou o melhor dos cenários, quando do nivelamento da capacidade produtiva frente à demanda dos clientes. 
Figura 1: Demanda x capacidade

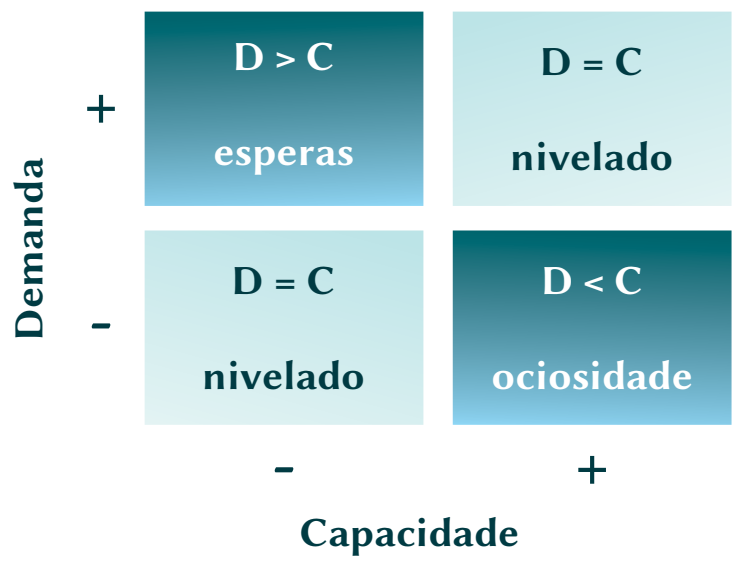

Fonte: Menezes (2010)

Há de se atentar ao hiato criado entre as decisões a serem tomadas relativas às variações de demanda dos clientes, a fim de se atender às necessidades de tempo, quantidade, prazo, local e manter ou aumentar a lucratividade da organização (MENEZES,2010).Para que haja uma melhor definição da capacidade produtiva versus o atendimento à demanda,é interessante que exista cooperação entre os atores da cadeia produtiva, a fim de melhorar o fluxo de informações e produtos. (LIMA; SOARES, 2010).

Para atender a um melhor nivelamento do atendimento à demanda, Gusmão et al. (2012) comentam da possibilidade de uso da ferramenta de métodos e tempos cronometrados como auxílio na obtenção de uma melhor capacidade produtiva, melhorando a eficiência geral da fábrica, com consequente redução de custos e melhora na lucratividade. Lacerda e Teixeira (2009) comentam sobre a disponibilização de terceirização, melhora na qualidade do produto e processo, turnos extras e utilização de horas-extras como opções para melhorias na capacidade produtiva das organizações.

Dentre as metodologias existentes para melhoria na capacidade produtiva, pode-se citar a Teoria das Restrições. A aplicação prática da metodologia pode ser verificada por meio de um modelo de gerenciamento da capacidade produtiva, desenvolvido por Pacheco et al. (2012), identificado pela restrição do sistema, subordinação dos recursos à restrição, passando pela definição da capacidade real do sistema até a elevação da capacidade do gargalo.

\subsection{Diagrama de espaguete}

A figura 2 representa o diagrama de espaguete, que é utilizado para identificar o caminho percorrido por um operador, materiais ou ferramental e a distância total. De posse da ferramenta aplicada, definem-se alterações no layout da organização, a fim de reduzir o percurso percorrido e, consequentemente, o tempo de processo, objetivando eliminar eventuais desperdícios na execução das atividades. (YAMADA; MARINS,2010). A aplicação da ferramenta pode trazer benefícios como, por exemplo, etapas no processo onde o mesmo possa ser puxado, possibilidade de pontos de controles e a possibilidade de se criar um fluxo contínuo no processo. (SILVA; RENTES, 2012). 


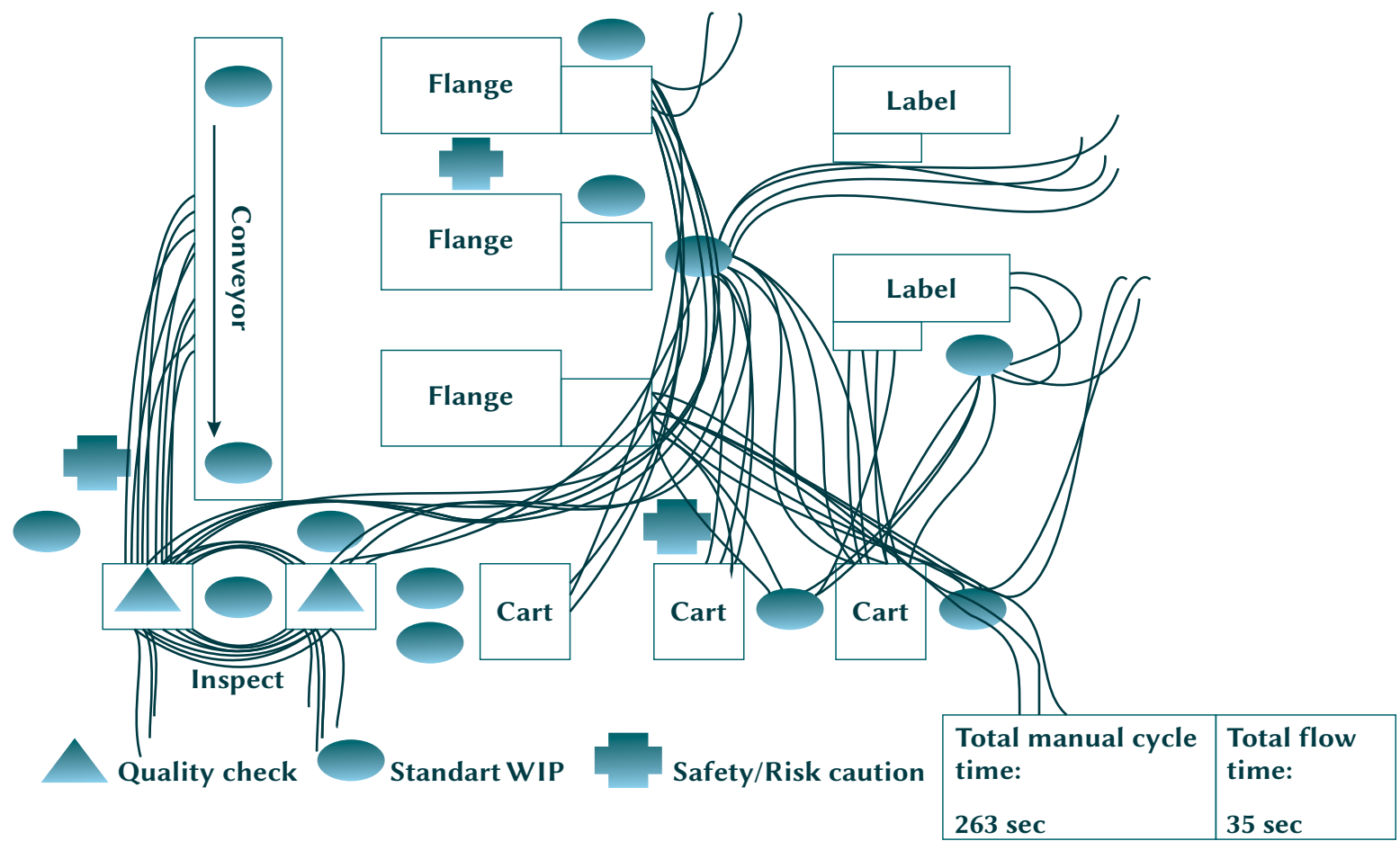

Fonte: Labach (2010)

Hayashi (2013) cita que o Lean Production visa à redução de custos através da redução e eliminação de atividades que não agregam valor ao cliente final, podendo ser adotado o diagrama de espaguete como ferramenta auxiliar para obtenção desse objetivo. Labach (2010) observa a redução de movimentos e de outras atividades que não agregam valor, em estudo realizado em um evento kaizen. As linhas em azul demonstram os movimentos necessários realizados pelo operador para movimentação de materiais entre as operações.

\subsection{Tipos de processos produtivos}

De maneira geral, podem ser definidos em quatro tipos de processos produtivos dentro das organizações, quais sejam: por projeto,jobbing, lotes ou contínuos. Monteiro, et al. (2010) comentam em seu trabalho sobre o impacto de cada tipo de processo produtivo.

Processo por lote pode ser entendido como aquele em que exista uma maior quantidade e variedade de produtos, necessitando de trocas de recursos (set ups) para confecção dos produtos (NOGUEIRA; OLIVEIRA, 2009). Relativo ao processo produtivo por lotes, tema do presente trabalho, verifica-se que esse sistema gera uma redução nos custos envolvidos na fabricação. Por outro lado, acaba gerando uma grande quantidade de produtos estocados. (SOUZA et al., 2011). 


\section{DESENVOLVIMENTO DO ESTUDO: COLETA DE DADOS}

Foram analisados os dados das quantidades de peças costuradas nos últimos dois anos, como pode ser visto nos gráficos 1 e 2 .

A EMPRESA UTILIZA O SISTEMA EMPURRADO HÁ 18 ANOS. CONTA COM TRÊS CLIENTES PRINCIPAIS, DISTRIBUÍDOS NAS CIDADES DE GuABIRUBA - SC E Brusque - SC. O produto PRINCIPAL FABRICADO SÃO CAMISETAS BÁSICAS NOS TAMANHOS P-M-G-GG ADULTO NO SEGMENTO FEMININO E MASCULINO.

Todas as informações coletadas junto ao socioproprietário foram analisadas confrontando-se com os temas abordados no estudo.

Gráfico 1: Peças costuradas em 2012

\section{Quantidade de peças costuras 2012}

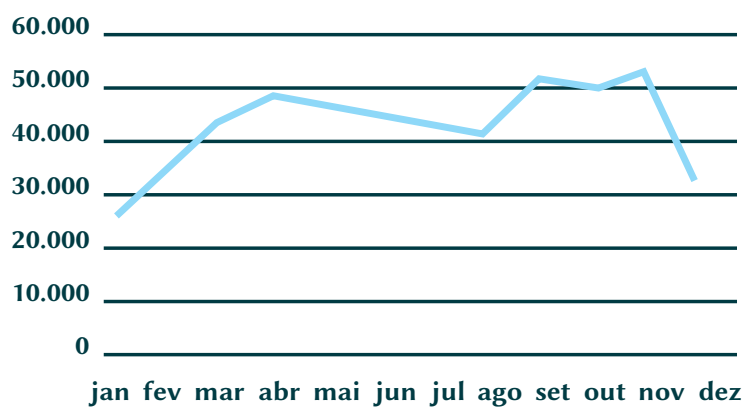

Colaboradores em 2012

14 costureiras

4 auxiliares de costureiras
Gráfico 2: Peças costuradas em 2013

\section{Quantidade de peças costuras 2013}

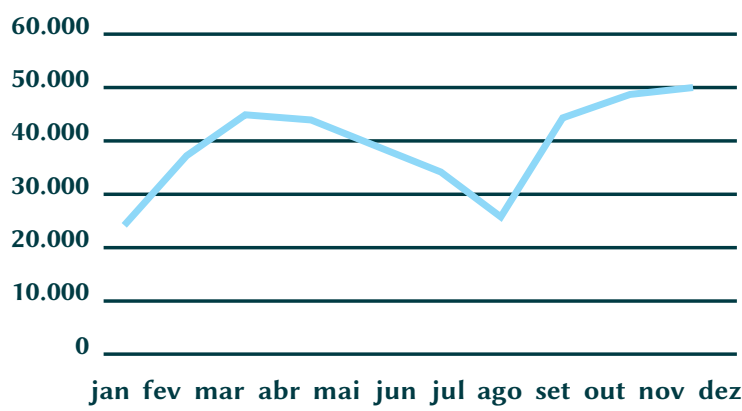

Colaboradores em 2013

\section{2 costureiras}

4 auxiliares de costureiras.

Fonte: Confecções Cavichioli (2013)

\subsection{Tratamento dos dados}

As informações obtidas da literatura possibilitaram as análises de conteúdo que resultaram em três temas centrais: célula de confecção, previsão da demanda e capacidade produtiva que auxiliaram na elaboração das perguntas ao socioproprietário. A partir das informações obtidas, foi possível analisar que, com a situação atual da empresa, esta define sua previsão de demanda baseada única e exclusivamente na sua capacidade produtiva. 


\section{ESTUDOS DE CASO}

A empresa em estudo, Confecção Cavichioli, é uma micro empresa, fundada em 1995, especializada em prestação de serviço de costura. A empresa funciona com um turno fixo de oito horas de trabalho. Para iniciar a análise dos dados, realizou-se a comparação entre a demanda infinita, ou seja, a necessidade real do mercado sem considerar capacidade produtiva, com a produção realizada com base em histórico.

Gráfico 3: Produção de demanda em 2012

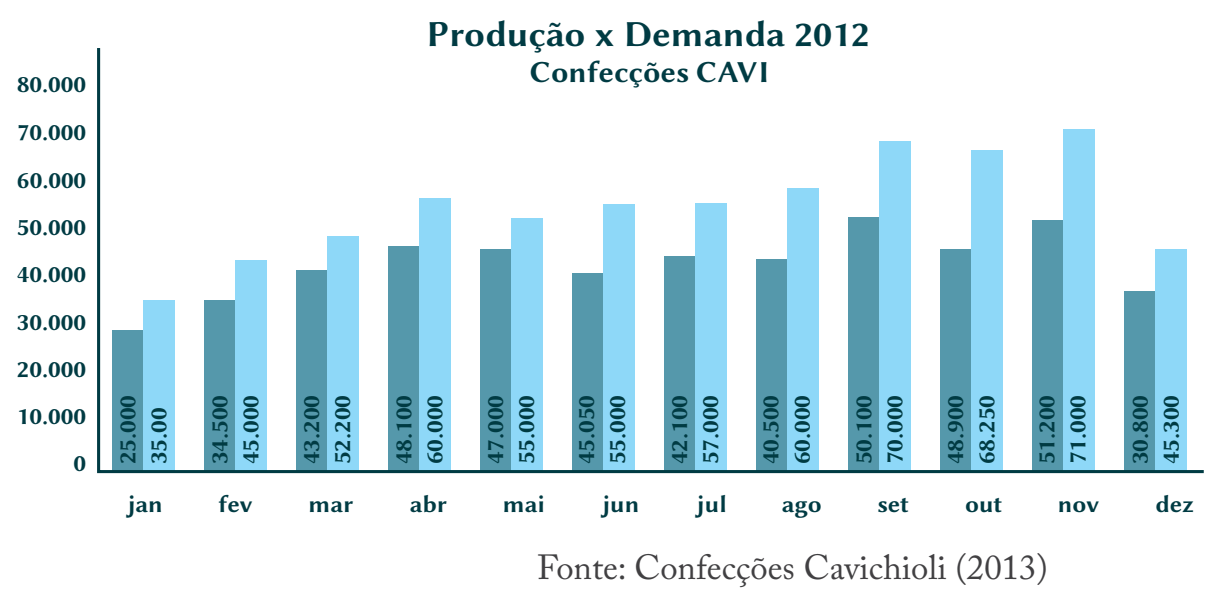

Produção realizada

Demanda infinita

Gráfico 4: Produção de demanda em 2013

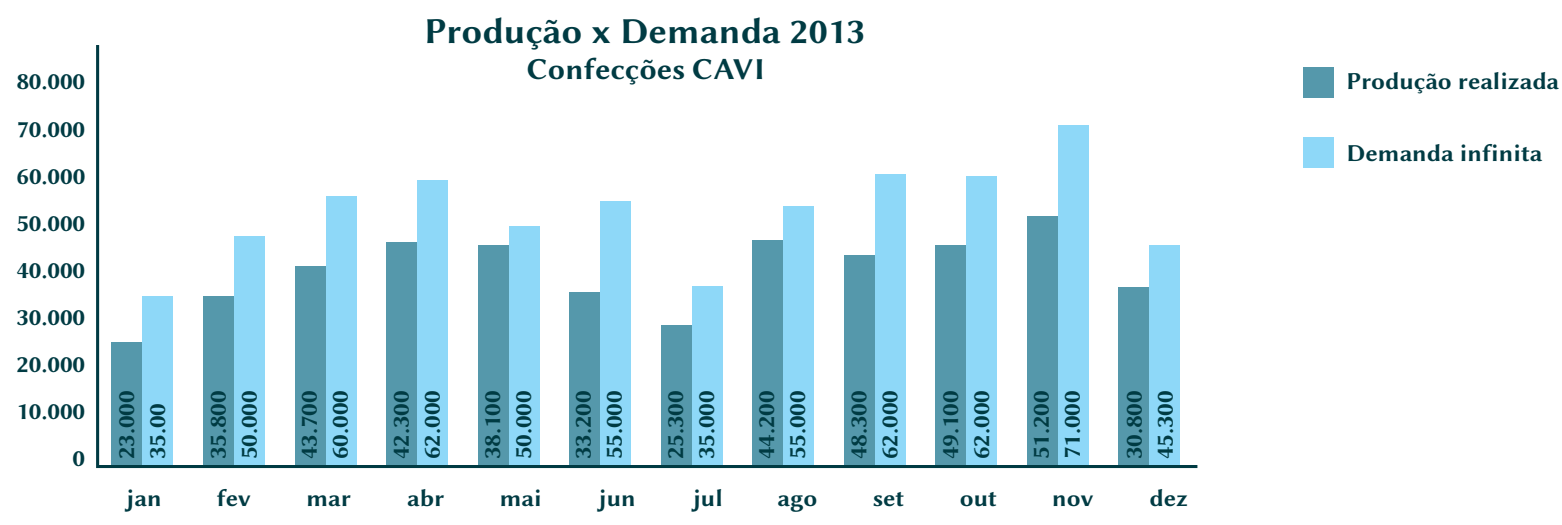

Fonte: Confecções Cavichioli (2013)

Com base no histórico, procurou-se entender qual a causa raíz de não estar absorvendo toda a demanda solicitada, uma vez que a empresa só está trabalhando com um turno de trabalho. $\mathrm{O}$ estudo demonstrou que o principal fator era a falta de mão de obra qualificada, no caso costureiras. Ou seja, a empresa perdia cerca de $25 \%$ de adicional de produção, por falta de mão de obra. Atualmente, a empresa possui oito costureiras e quatro manuais (auxiliares de costureira). 
O estudo ficou focado em otimizar o fluxo da confecção para aumentar a produtividade. $\mathrm{Na}$ figura 3 temos a representação do fluxo de valor das atividades da Confeccção Cavichioli.

Atualmente a empresa possui os seguintes equipamentos: 12 Overlock, seis Máquinas de Cobertura/Galoneira, uma Esteira
Automática de Cobertura/Galoneira, cinco Mesas de Preparação/Inspeção, um Revisador. Considerando esses equipamentos e o layout atual da empresa, avaliou-se o fluxo de movimentação conforme o diagrama de espaguete representado na figura 3 .

Figura 3: Fluxo das atividades da confecção em 2013

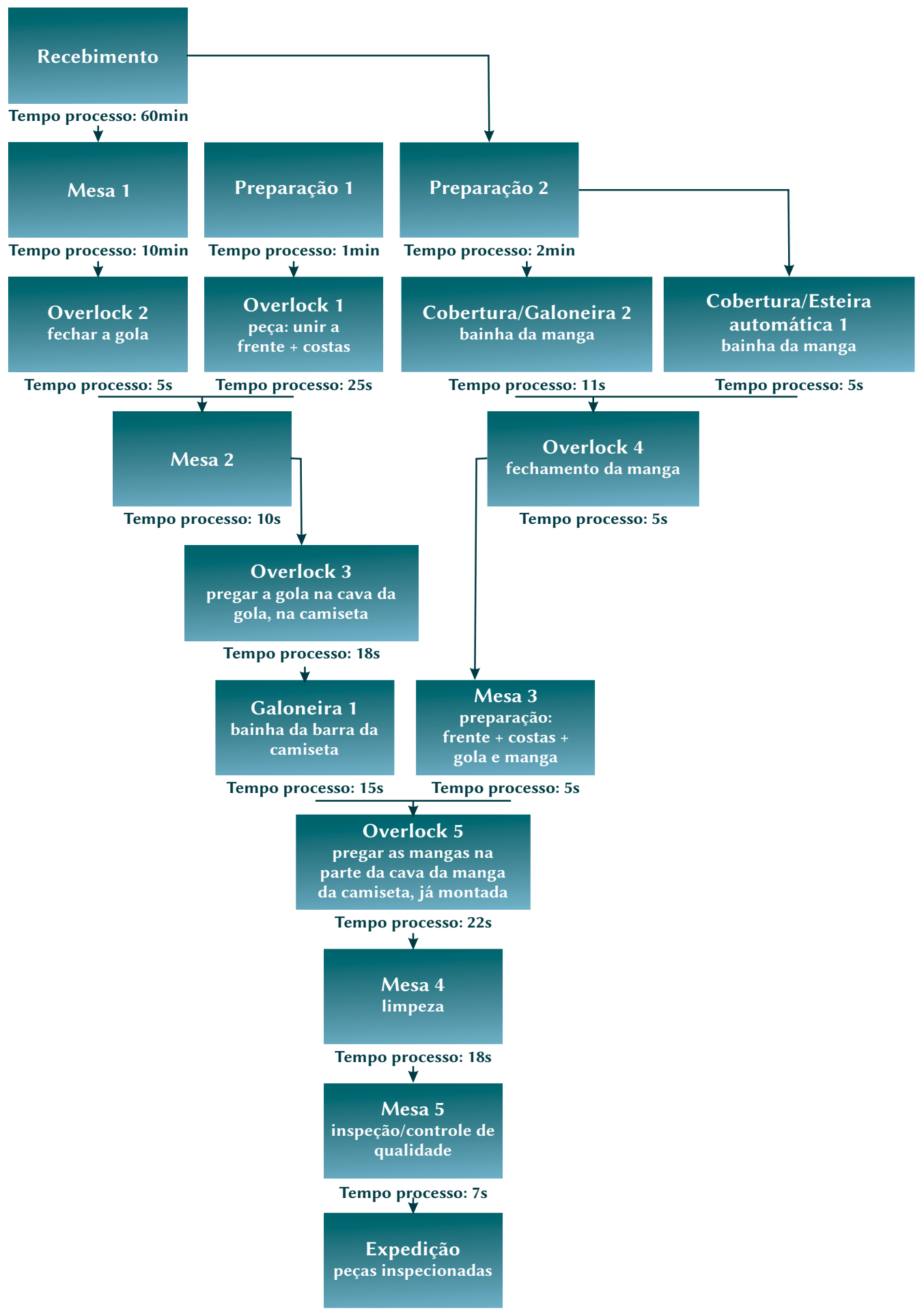

Fonte: Confecções Cavichioli (2013) 
Figura 4: Layout da empresa em forma de Diagrama de espaguete

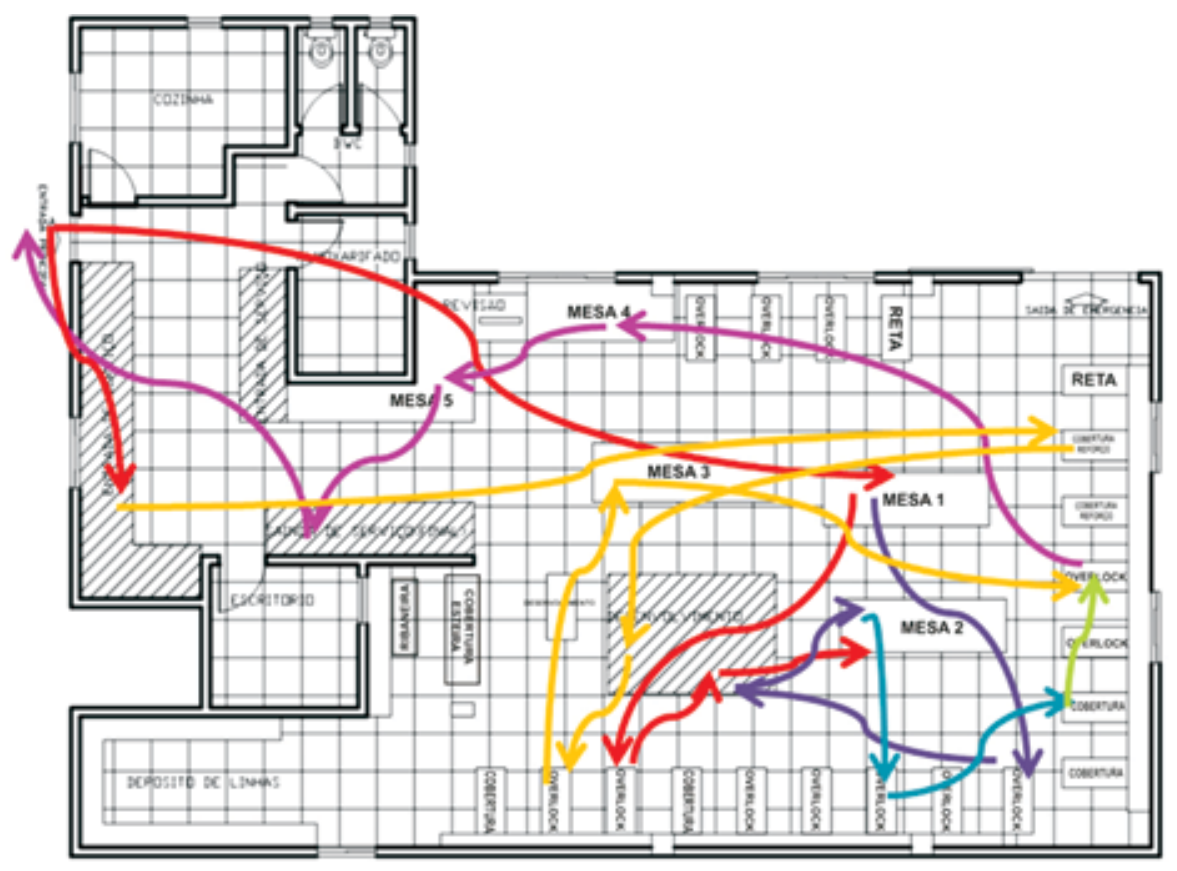

Fonte: Confecções Cavichioli (2013)

Pode-se observar os diversos cruzamentos na movimentação, isso devido ao layout atual ser departamentalizado e não existir diferenciação entre os lotes de produção (tamanhos P-M-GGG). Essa forma de layout dificulta o fluxo de informação e aumenta o excesso de movimentação, perdendo tempo produtivo. $\mathrm{Na}$ tabela 1 é apresentada a sequência operacional para a realização da montagem de uma camiseta masculina.

Tabela 1: Sequência operacional de uma camiseta masculina

\begin{tabular}{|l|l|}
\hline \multicolumn{2}{|c|}{ SEQUÊNCIA OPERACIONAL DE UMA CAMISETA MASCULINA } \\
\hline \multicolumn{1}{|c|}{ OPERAÇÃO } & \multicolumn{1}{c|}{ MAQUINÁRIO } \\
\hline $1^{\circ}$ Montagem frente e costa & Manual \\
\hline $\begin{array}{l}2^{\circ} \text { Fechar dois ombrose as duas laterais } \\
\text { da camiseta }\end{array}$ & Overlock \\
\hline $3^{\circ}$ Fechar a gola & Overlock \\
\hline $4^{\circ}$ Virar a gola dobrando-a & Manual \\
\hline $5^{\circ}$ Pregar a gola do decote & Overlock \\
\hline $6^{\circ}$ Fazer a bainha das duas mangas & $\begin{array}{l}\text { Esteira automática cobertura/ } \\
\text { galoneira }\end{array}$ \\
\hline
\end{tabular}




\begin{tabular}{|l|l|}
\hline \multicolumn{2}{|c|}{ SEQUÊNCIA OPERACIONAL DE UMA CAMISETA MASCULINA } \\
\hline \multicolumn{1}{|c|}{ OPERAÇÃO } & \multicolumn{1}{c|}{ MAQUINÁRIO } \\
\hline $\begin{array}{l}7^{\circ} \text { Fechar a manga com costura de } \\
\text { arremate }\end{array}$ & Overlock \\
\hline $\begin{array}{l}8^{\circ} \text { Virar as duas mangas para o lado } \\
\text { direito }\end{array}$ & Manual \\
\hline $9^{\circ}$ Pregar as duas mangas na cava & Overlock \\
\hline $10^{\circ}$ Fazer bainha na barra da peça & Cobertura/galoneira \\
\hline $\begin{array}{l}11^{\circ} \text { Realizar limpeza e inspeção da } \\
\text { camiseta }\end{array}$ & Manual \\
\hline
\end{tabular}

Fonte: Confecções Cavichioli (2013)

\subsection{Proposta de layout}

Com a avaliação do fluxo atual e com intuito de reduzir a movimentação, criou-se a proposta de layout em célula. Com o layout em célula, além de reduzir o fluxo de movimentação, principalmente das costureiras que são mão de obra escassa, é possível reduzir consideravelmente o estoque em processo (WIP - work in process). $\mathrm{Na}$ figura 5 temos a representação do layout proposto:

Figura 5: Layout proposto

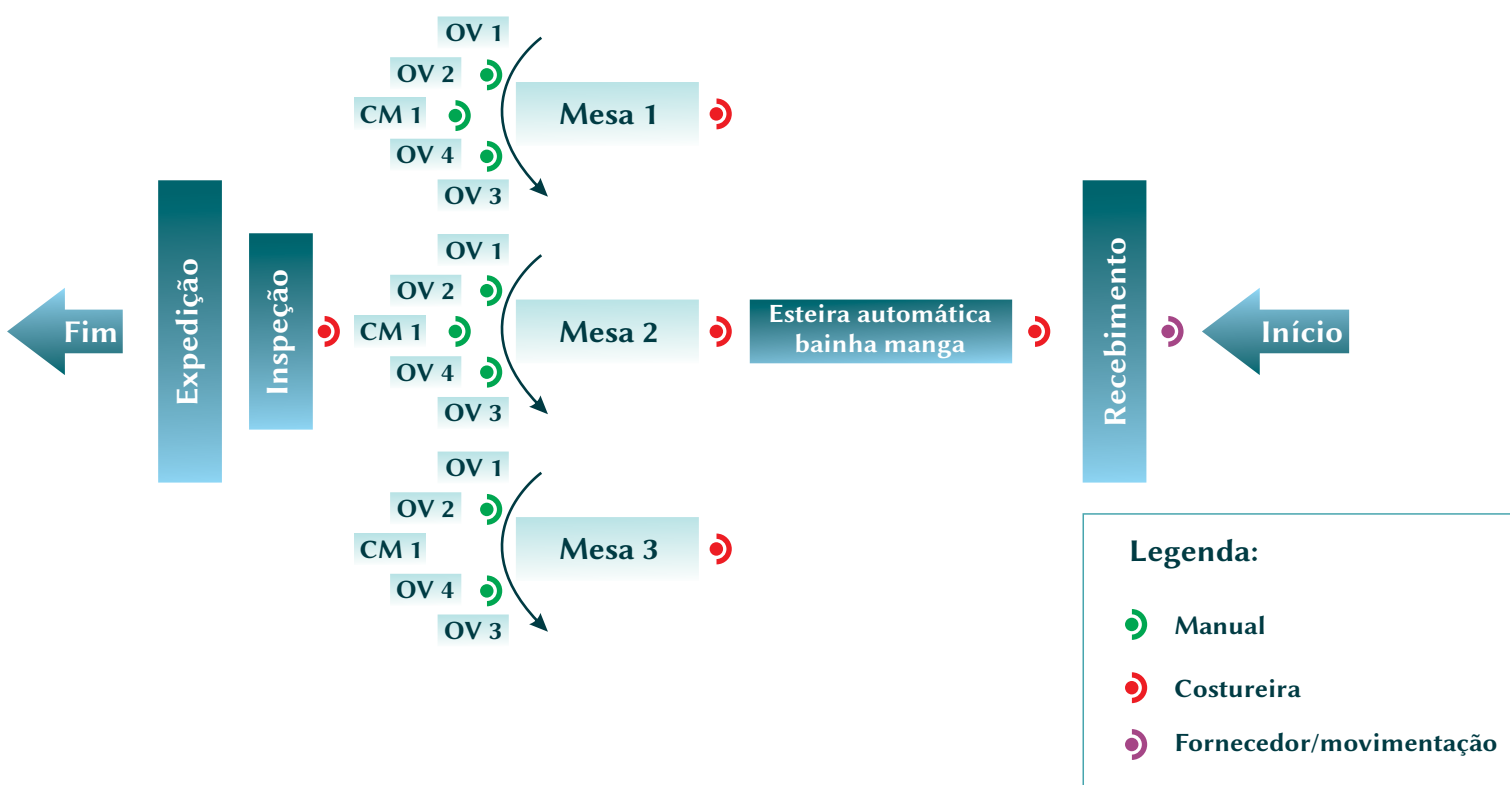

Fonte: Confecções Cavichioli (2013) 
Sendo:

OV1 - Máq. Overlock para costura da parte frontal + parte traseira $=$ Peça 1

OV2 - Máq. Overlock para costura da gola

CM1-Máq.de CoberturaManual parabainha da Peça 1

OV4 - Máq. Overlock para costura final da Peça $1+$ Gola + Manga

OV3 - Máq. Overlock para fechamento da Manga

Mesa 1/2/3 - Mesa para separação das partes, inspeção e abastecimento da célula

Esteira Automática - Máq. de Cobertura Automática para as Mangas

Inspeção - Mesa de Inspeção Final, com utilização revisador

JUNTAMENTE COM O LAYOUT EM CÉLULA, FOI PROPOSTO O TIPO DE SISTEMA PRODUTIVO POR BATELADA, OU SEJA, CADA CÉLULA SÓ IRÁ FAZER UM TAMANHO DE CAMISA POR VEZ, PARA, DESSA FORMA, REDUZIR OS PROBLEMAS DE QUALIDADE.

Na parte do quadro de mão de obra, incluiu-se mais uma pessoa para ser o fornecedor (mesmo nível de cargo de um manual) para separar os lotes por tamanho e encaminhar para cada célula,bem como ser o helpchain para problemas de abastecimento.

\subsection{Capacidade atual $\mathrm{x}$}

\section{capacidade proposta}

A capacidade atual da Confecção Cavichioli, sem considerar as costureiras terceirizadas, é dividida da seguinte forma:

Mesa $1=3 \mathrm{~s}$

$\mathrm{OV} 2=5 \mathrm{~s}$

Mesa $2=10$ s

$\mathrm{OV} 3=18 \mathrm{~s}$

Galoneira 1 (Cobertura Manual)= 15s

$\mathrm{OV} 5=22 \mathrm{~s}$

Mesa 3= 5s

$\mathrm{OV} 1=25 \mathrm{~s}$

$\mathrm{OV} 4=5 \mathrm{~s}$

Esteira Automática $=5 \mathrm{~s}$

Preparação 1= 3s

Preparação 2= 3s

Mesa $4=18$ s

Mesa $5=7 \mathrm{~s}$

Tem-se que:

- Tempo com Máq. (tempo costureira)=95s e, dividindo por oito mãos de obra, tem-se que o TC (tempo de ciclo $)=12$ s.

- Tempo Periférico (tempo manual) $=49 \mathrm{~s}$ e, dividindo por quatro mãos de obra, tem-se que o $\mathrm{TC}=12,2 \mathrm{~s}$.

- Capacidade $100 \%$ Eficiência= Tempo disponível/TC, ou seja, 2.400 pçs por dia OU 52.800 pçs/mês.

- Capacidade 85\% Eficiência= Tempo disponível/ TC *85\%, ou seja, 2.040 pçs por dia OU 44.880 pçs/mês. 
Sendo que toda análise de capacidade foi baseada na mão de obra atual e esse fator varia de acordo com a época do ano e a disponibilidade de dias úteis no mês.

JÁ NA CAPACIDADE DE CÉLULA PROPOSTA, TOMOU-SE O CUIDADO DE REDUZIR AS MOVIMENTAÇÕES, COM INTUITO DE TER UM MELHOR APROVEITAMENTO DAS COSTUREIRAS NAS ATIVIDADES QUE AGREGAM VALOR.

Dessa forma, chegou à seguinte distribuição macro dos tempos:

Célula 1 e Célula 2, considerando três costureiras e um manual:

$\mathrm{OV} 1=25 \mathrm{~s}$

$\mathrm{OV} 2=5 \mathrm{~s}$

$\mathrm{CM} 1=15 \mathrm{~s}$

$\mathrm{OV} 4=5 \mathrm{~s}$

$\mathrm{OV} 3=18 \mathrm{~s}$

Mesa 1= 3s

Mesa 2 $=10$ s

Mesa 3= 5s

Preparação $1=3 \mathrm{~s}$

Preparação 2= 3s

Inspeção= $3 \mathrm{~s}$
Tem-se que:

- Tempo com máquina (tempo para costurei$\mathrm{ra})=68 \mathrm{~s}$ e, dividindo por três mãos de obra, tem-se que o TC (tempo de ciclo $)=23 \mathrm{~s}$.

- Tempo Periférico (tempo para o manual)= $27 \mathrm{~s}$ e, dividindo por uma mão de obra, tem-se que o $\mathrm{TC}=27 \mathrm{~s}$.

- Capacidade 100\% Eficiência= Tempo disponível/TC, ou seja, 1.252 pçs por dia OU 27.547 pçs/mês.

- Capacidade 85\% Eficiência= Tempo disponível/ TC *85\%, ou seja, 1.064 pçs por dia OU 23.415 pçs/mês.

Já para Célula 3, que possui apenas duas costureiras e um manual, tem-se:

- Capacidade $100 \%$ Eficiência= Tempo disponível / TC, ou seja, 848 pçs por dia OU $18.636 \mathrm{pçs} / \mathrm{mês}$.

- Capacidade 85\% Eficiência= Tempo disponível/ TC *85\%, ou seja, 720 pçs por dia OU 15.840 pçs/mês.

Para o cálculo da nova capacidade, levou-se em consideração o acréscimo de mais duas mãos de obra, uma para ser o fornecedor periférico e um manual de máquina (treinado para operar a Esteira Automática), dessa forma as costureiras, que têm o custo mais alto para a empresa, seriam melhor ocupadas com atividades de maior valor agregado, resultando, com isso, uma capacidade de 62.670 peças/mês, ou seja, um aumento de $28,4 \%$ na capacidade, considerando apenas um turno de trabalho.

As demais atividades que possuem tempos menores e não são gargalos para o processo foram realocadas em atividades periféricas ao fluxo: recebimento, inspeção final e expedição. 


\section{CONSIDERAÇÕES FINAIS}

Devido à necessidade de rápida adaptação de demanda que o setor de confecção exige para o mercado, aumenta cada vez mais a necessidade de ter sistemas produtivos que trabalhem com baixos níveis de estoque em processo e, ao mesmo tempo, tenham o tempo takt adequado. Com isso, existe a necessidade de se implantar um sistema produtivo em célula e por batelada, para evitar o desperdício da movimentação e reduzir os problemas de qualidade.
Através do layout proposto e tomando como base a demanda infinita desejada em 2013, se o layout proposto e as adequações de mão de obra já tivessem sido implantadas, a nova capacidade atenderia a cerca de $83 \%$ do volume solicitado, considerando apenas a capacidade interna. Dessa forma, pode-se observar que além de adequar o layout e o tipo de sistema produtivo, é importante entender qual takt time que o processo precisa entregar e balancear as atividades das costureiras e manuais para garantir um melhor balanceamento e reduzir os desperdicios. 


\section{ADEQUACY OFTHE PRODUCTION OF SUBCONTRACTED SERVICES OF A GARMENTS MANUFACTURE: A CASE STUDY}

\begin{abstract}
This article is a case study that aims to examine the adequacy of subcontracted production services of a small company in the garments manufacture sector in thecity of Guabiruba-SC, which is part of a segmententitled to provide services of sewing of knitwear articles of basic line. The data were qualitatively investigated by applying a questionnaire previously developed by the authors, and answered by the co-owner of the factory that we call here Cavichioli Clothing. The contact was made personally, obtaining information about the demand history of the last two years, production capability, production flow, layout and use of manufacturing cell. Starting from proposals of Tubino (2009), Slack et al. (2002), Toledo (1992) and others cited in this article, it was possible to compare the literature with the practice of the investigated supply chain. It was identified that the demand forecast, based on the company's production capability was more efficient than that related to the production history and that the modification of the layout of the machinerytogether with the switch to a production system in cell and per batch, showed the best result to meet the demand required by the market.
\end{abstract}

KEYWORDS: Clothing

Manufacturing.

Manufacturing Cell. Demand

forecast. Productive capability.

\section{REFERÊNCIAS}

ARAUJO, M. Tecnologia do Vestuário. Lisboa: Fundação Calouste Gulbenkian, 1996.

ARAUJO, M.; MELO e CASTRO, E. M. Manual de Engenharia Têxtil. v. 2. Lisboa: Fundação Calouste Gulbenkian, 1984.

BRASIL, H. G. A empresa e a estratégia de terceirização. Revista de Administração de Empresas, São Paulo, 1993.

CORREAA, H. L.; GIANESI, I. G. N; CAON M. Planejamento, Programação e Controle da Produção. 5. ed. São Paulo: Atlas, 2012.

GIL, A. C. Métodos e Técnicas de Pesquisa Social. 5. ed. São Paulo: Atlas, 1999.

GIOSA, L. A. Terceirização: uma abordagem estratégica. São Paulo: Pioneira, 1993.

GUSMÃO, A. P. H. et al. Análise da Capacidade Produtiva de Uma Indústria de Transfers Utilizando o Estudo dos Tempos. Bento Gonçalves: XXXII Encontro Nacional de Engenharia de Produção - ENEGEP, 2012.

HAYASHI, A. P. Aplicação das Técnicas Enxuta Como Forma de Melhorar o Desempenho na Estratégia de Produção em Uma Indústria de Autopeças Elétricas da Região Centro-Oeste do Estado de São Paulo. Salvador: XXXIII Encontro Nacional de Engenharia de Produção - ENEGEP, 2013.

JOHNSTON, R.; CLARK, G. Administração de Operações de Serviço. São Paulo: Atlas, 2010.

LABACH, E. J. Using Standard Work Tools For Process Improvement. Jornal de negócios sobre estudo de caso, Volume VI, n. 1, 2010.

LACERDA, J. M.; TEIXEIRA, M. A. Aumento da Capacidade de Produção. Belo Horizonte: $4^{\circ}$ SSIA, 2009.

LIMA, L. C. O.; SOARES, P. R. Inovações e Reestruturação da Cadeia Produtiva Têxtil do Algodão. Campo Grande: 48 SOBER, 2010.

MENEZES, L. Gerenciamento de Capacidade e Demanda em Operações de Serviços: Um estudo exploratório em uma central de atendimento ao cliente. São Carlos: XXX ENGEEP, 2010.

MONTEIRO, R.; LELIS, E. C.; RODRIGUES, E. F. Logística e Produção: Impacto dos Estoques na Velocidade de Processo de Manufatura.

Resende: VII Simpósio de Excelência em Gestão e Tecnologia, 2010. 


\section{SOBRE OS AUTORES}

NOGUEIRA, N. F; OLIVEIRA, A. P. V. D. Análise do Sistema Produtivo de Uma Empresa Metalúrgica de Pequeno Porte. Pará de Minas: Revista Digital FAPAM v. 1, n. 1, p. 231-260, 2009.

PACHECO, D. A. J. et al. Modelo De Gerenciamento da Capacidade Produtiva: Integrando Teoria das Restrições e o Índice de Rendimento Operacional Global (IROG). Florianópolis: Revista Eletrônica ABEPRO, v. 12, n. 3, p. 806-826, 2012.

POPADIUK, S; SANTOS, A. E. M. dos.

Conhecimentos tácito, explícito e cultural no planejamento da demanda. São Paulo: Revista de Gestão da Tecnologia e Sistemas de Informação, v. 7, n. 2, p. 205-226, 2010.

REZENDE, M. L. A. PCP Básico na Indústria Têxtil. Rio de Janeiro: SENAI/CETIQT, 1992.

SILVA, A. L.; RENTES, A. F. Um Modelo de Projeto de Layout Para Ambientes Job Shop com Alta Variedade de Peças Baseado nos Conceitos da Produção Enxuta. São Carlos: Revista Gestão \& Produção, v. 19, n. 3, p. 531-54, 2012.

SLACK, N.; CHAMBERS, S.; JOHNSTON, R. Administração da produção. São Paulo: Atlas, 2002.

SOUZA, E. P. M. et al. Categorização dos sistemas produtivos sob um enfoque multidimensional: uma análise da natureza dos processos de produção do semiárido nordestino. Campina Grande: VI Simpósio de Engenharia de Produção da Região Nordeste, 2011.

TOLEDO Jr., F. B. Balanceamento de Linhas. 6. ed. Mogi das Cruzes: O\&M, 1992.

TUBINO, D. F. Planejamento e Controle da Produção: teoria e prática. 2. ed. São Paulo: Atlas, 2009.

YAMADA, N. E.; MARINS, F. A. S. M. Aplicação de Conceitos da Manufatura Enxuta no Processo de Pré-Equipagem de Asas. São Paulo: XIII Simpósio de Administração da Produção, Logística e Operações Internacionais - SIMPOI, 2010 .

Data de recebimento: 05/08/14

Data de aprovação: 20/11/14

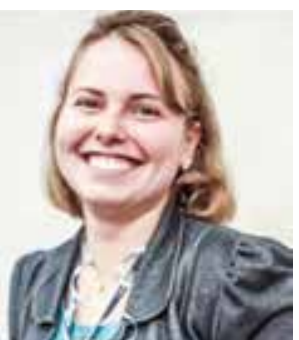

Alini Cavichioli

Designer de Moda graduada pela Associação educacional do vale do Itajaí-Mirim (UniasselviAssevim). Especialista em Gestão Estratégica Empresarial pela Associação educacional do vale do ItajaíMirim (Uniasselvi-Assevim). Mestranda em Engenharia da Produção pela Sociedade Educacional de Santa Catarina - Sociesc Joinville/SC. Atua como Especialista do Vestuário no SENAI/SC em Brusque, atuando como professora e instrutora nos cursos de segmentos de nível de Aprendizagem, Qualificação e Técnico, nas áreas de confecção e têxtil e tecnologia. É também professora no curso de graduação em bacharel em Design de Moda pela Associação Educacional do Vale do ItajaíMirim (Uniasselvi-Assevim) na disciplina de Tecnologia da Confecção. 


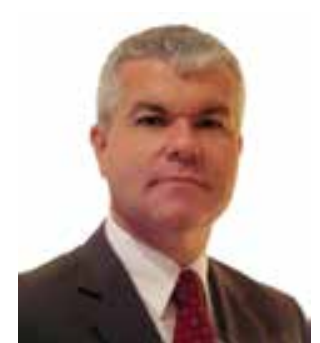

Antonio José dos

Santos

EngenheiroMecânicograduado pela Universidade do Estado de Santa Catarina (Udesc) e mestre em Engenharia deProdução pela Universidade Federal de Santa Catarina (Ufsc). Doutorando em Ciência e Engenharia de Materiais pela Udesc. Tem certificação Blackbelt na metodologia 6 Sigma pela Six Sigma Associates (EUA) e é Lead Assessor para Sistemas de Gestão da Qualidade padrão NBR ISO 9001. Atuou por mais de 20 anos na indústria de eletroeletrônicos na gestão de processos de manufatura e no desenvolvimento de novos produtos. É especialista em Educação e professor dos cursos de graduação, pós-graduação (especialização e mestrado) e extensão da Unisociesc no Paraná e em Santa Catarina.

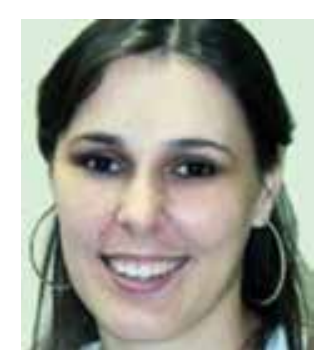

\section{Cristiane Luiza Bleich} Vetore

Engenheira de Produção graduada pela Unerj, Jaraguá do Sul/SC. É especialista em Lean

Manufacturing pela Furb, Blumenau/SC. Mestranda em Engenharia da Produção pela Sociedade Educacional de Santa Catarina Sociesc - Joinville/SC. Atua em projetos de melhoria,Lean Manufacturing,Mapeamento de Fluxo de Valor - MFV e Planos de Ação - PA. Coordenava projetos do Lean Office. Realiza pesquisas de mercado (benchmark) visando à redução de custos em produtos.

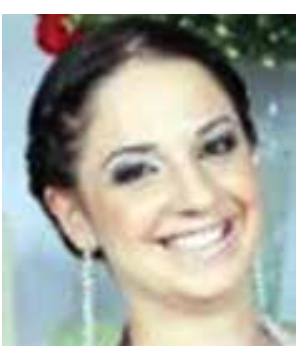

Daniele Cristina Gelain Rezende

É engenheira de Produção e Sistemas graduada pela Universidade do Estado de Santa Catarina (Udesc) e mestranda na Unisociesc. Tem certificação Greenbelt na metodologia 6 Sigma pela Six Sigma Associates e Certificado de MTM 1 e UAS (Methods-Time Measurement) pelaMTM Association. Atua na indústria da linha branca, trabalhou com planejamento e controle da produção e, atualmente, trabalha com planejamento estratégico, dimensionamento fabril, utilizando métodos e tempos.

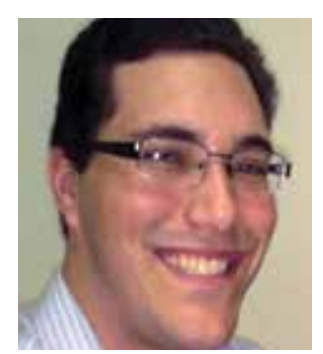

\section{Giancarlo Steffani}

Tecnólogo e m Eletromecânica pela Universidade da Região de Joinville, especialista em Ensino Superior e Engenharia de Produção, MBA em Logística. É mestrando em Engenharia de Produção.Lead Assessor NBR ISO 9001, ministrou treinamentos, consultoria e auditoria. Atuou na indústria automotiva com implantação de normas ISO/ TS 16949 e ISO 14001, assumindo funções de Supervisão e Gerência Geral. Docente desde 2004 em cursos de nível técnico, superior e pós-graduação, nas disciplinas de Gestão da Produção, Gestão da Qualidade, Logística e Empreendedorismo. 


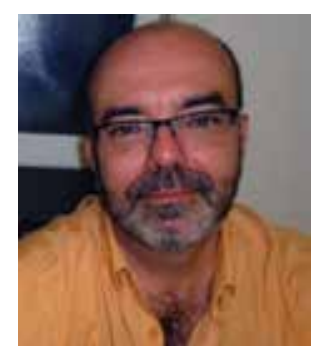

Wallace Nóbrega Lopo

Engenheiro Mecânico com ênfase em Têxtil,graduado pela Faculdade de Engenharia Industrial de São Paulo (FEI), Bacharel em Administração graduado pela Universidade São Francisco de Itatiba/SP (USF), MBA em Gestão Empresarial pela Fundação Getúlio Vargas do Rio de Janeiro (FGV), MBA em Gestão de Empresas Têxteis pelo Instituto Blumenauense de Ensino Superior de Blumenau(IBES) eMestrando em Engenharia de Produção pelo CentroUniversitário Tupy de Joinville (Unisociesc).É professor e coordenador técnico do Curso Superior em Tecnologia da Produção Têxtil e de Pós-Graduação MBA Gestão da Cadeia Têxtil da Unifebe em parceria com o SENAI de Brusque; professor dos cursos de qualificação e técnico na área têxtil pelo SENAI de Brusque. Atua há 28 anos na indústria têxtil. 